\title{
A Educação Ambiental e seus Desafios: um olhar acerca das escolas municipais de São Sebastião da Amoreira - PR
}

\section{Environmental Education and its Challenges: a look at municipal schools in São Sebastião da Amoreira - PR}

\section{La Educación Ambiental y sus Desafíos: una mirada alas escuelas municipales de São Sebastião da Amoreira - PR}

\author{
Suellen Jane Correia' \\ Rodrigo de Souza Poletto ${ }^{2}$
}

\begin{abstract}
Resumo
O objetivo deste trabalho é compreender como os professores do Ensino Fundamental I abordam a Educação Ambiental com seus alunos. Esta pesquisa foi realizada em duas escolas municipais de São Sebastião da Amoreira-PR, sendo que, para coleta de dados, utilizamos questionários diagnósticos, os quais foram aplicados aos professores de forma individual. As informações obtidas deste instrumento de coleta foi o corpus da pesquisa e para analisá-las, apoiamo-nos na Análise Textual Discursiva. Após a análise dos dados, os resultados evidenciaram que os professores abordam essa temática somente em datas simbólicas ou de forma pontual, bem como se utilizam de exemplos distantes da realidade do aluno e ineficazes para mudar o comportamento do estudante e melhorar as condições em seu entorno.
\end{abstract}

Palavras-chaves: Educação Ambiental Formal. Processo de Ensino. Prática Docente.

\begin{abstract}
The objective of this work is to understand how Elementary School teachers approach Environmental Education with their students. This research was carried out in two municipal schools in São Sebastião da Amoreira-PR, and, for data collection, we used diagnostic questionnaires, which were applied to teachers individually. The information obtained from this collection instrument was the corpus of the research and to analyze it, we rely on the Discursive Textual Analysis. After analyzing the data, the results showed that teachers only approach this topic on symbolic dates or in a timely manner, as well as using examples that are distant from the student's reality and ineffective in changing the student's behavior and improving the conditions around them.
\end{abstract}

Keywords: Formal Environmental Education. Teaching Process. Teaching Practice.

\section{Resumen}

El objetivo de este trabajo es comprender cómo los docentes de Primaria abordan la Educación Ambiental con sus alumnos. Esta investigación se llevó a cabo en dos escuelas municipales de São Sebastião da Amoreira-

1 Universidade Estadual de Londrina.

${ }^{2}$ Universidade Estadual do Norte do Paraná - UENP. 
PR y, para la recolección de datos, se utilizaron cuestionarios de diagnóstico, que se aplicaron a los docentes de manera individual. La información obtenida de este instrumento de recolección fue el corpus de la investigación y para analizarla nos apoyamos en el Análisis Textual Discursivo. Luego de analizar los datos, los resultados mostraron que los docentes solo abordan este tema en fechas simbólicas o de manera oportuna, además de utilizar ejemplos alejados de la realidad del alumno e ineficaces para cambiar el comportamiento del alumno y mejorar las condiciones a su alrededor.

Palabras Clave: Educación ambiental formal. Proceso de enseñanza. Práctica docente.

\section{Introdução}

Por mais que muitos compreendam a Educação Ambiental como um tema recente, os princípios ambientais surgiram há muitos anos, desde que o ser humano iniciava os cultivos na terra como forma de subsistência. Sempre se valendo do meio ambiente de maneira parcimoniosa, sem desperdício, utilizando apenas o necessário para sua sobrevivência, preservando seus recursos, de tal modo que esses princípios eram transmitidos para as gerações futuras. No decorrer dos anos, com a evolução das técnicas, o ser humano começou a ter mais informações sobre o meio; assim começou a explorar seus recursos de maneira desorientada, já que o objetivo passou a ser somente o capital e não mais a qualidade do meio ambiente (KRÜGER, 2001).

Desse modo, ao longo dos séculos, a destruição do meio ambiente não foi elemento de preocupação para a sociedade, ocasionando uma desenfreada degradação ambiental sem fronteiras tanto nos países desenvolvidos quanto nos países subdesenvolvidos (RAMOS, 1996). Ligado a isso esta o fato de que hoje em dia precisamos entender a inter-relação entre população, meio ambiente e desenvolvimento, com ênfase especial na noção de "capacidade de suporte" de cada população (HOGAN, 1993).

Nesse sentido, para amenizar esses efeitos, implantaram-se os princípios da Educação Ambiental, iniciados logo após a Segunda Guerra Mundial, mas que já eram praticados há muito tempo. Assim, compreende-se por Educação Ambiental as práticas aderidas - pela sociedade - que visam sensibilizar a população a fim de encontrar meios para auxiliar a proteção do ambiente em que vivemos. (BRANCALIONE, 2016).

Assim, iniciaram-se inúmeras formas de difundir socialmente aqueles princípios, uma delas foi por meio do ensino, a qual é uma ferramenta importantíssima no contexto social. Logo, espera-se que esse tema seja abordado por todas as disciplinas no ambiente escolar, uma vez que é multidisciplinar. No entanto, a realidade é um tanto quanto diferente do que há nas leis e decretos, pois muitas instituições não conseguem seguir essas deliberações.

Medeiros, Ribeiro e Ferreira (2020) relataram em seu trabalho que muitas dificuldades e desafios são encontrados no processo de desenvolvimento da Educação Ambiental dentro da Educação Básica, em especial no Ensino fundamental I das escolas públicas. Eles citaram que a grande parte dos professores sabem de suas responsabilidades socioeducativas, havendo consenso da importância do tema transversal Educação Ambiental. Todavia, há algumas dificuldades às quais os professores estão 
expostos, como a aplicação de atividades relacionadas a este tema, uma vez que alguns professores nunca participaram deste tipo de ação, falta de capacitação e a não inclusão da Educação Ambiental como temas transversais em seus planos de aula.

Outra dificuldade, de acordo com Medeiros Ribeiro e Ferreira (2020), é a falta de material didático, inclusive o próprio livro didático é defasado em conteúdos relacionados à questão ambiental, havendo necessidade de metodologias associadas a outros materiais que poderiam auxiliar, mas as escolas pesquisadas não disponibilizam, dificultando o trabalho. Ainda foi relatado a falta de compreensão e colaboração vinda da comunidade escolar em relação às práticas que colaborem para a melhoria do ambiente.

No trabalho de Lucatto e Talomani (2018), foi relatado que os professores trabalhavam a Educação Ambiental apenas esporadicamente, de forma tradicional e descontextualizada da realidade local, sem a existência de quaisquer articulações entre as disciplinas. Também ficou evidente a maneira intuitiva como os trabalhos, ditos interdisciplinares, vinham sendo realizados naquela escola.

Portanto, o objetivo deste trabalho é compreender como os professores das escolas municipais de São Sebastião da Amoreira - PR abordam a Educação Ambiental com seus alunos.

\section{Linha do tempo da Educação Ambiental}

A temática ambiental ainda é considerada recente se comparada as outras, pois foi a partir de 1960 que iniciaram as primeiras percepções a respeito da Educação Ambiental. Destarte, dois anos depois, surgiu um dos marcos referente a essa temática, o livro Primavera silenciosa, da autora Rachel Carson, o qual trazia vários pontos ambientais pertinentes naquele período, algum deles era o uso incorreto do meio ambiente, uso excessivo dos produtos químicos entre outros temas (DIAS, 1998).

Assim sendo, foi nesse momento que começaram os primeiros burburinhos sobre as questões ambientais, até naquele momento não eram mencionadas; assim, essa limitação de informação fez com que a Educação Ambiental passasse por inúmeros percalços. Alguns anos depois, especificamente em 1965, começaram a mencionar algumas percepções referente ao que seria o conceito de Educação Ambiental, no entanto, "remetia-se a uma definição mais relacionada com a preservação dos sistemas de vida". (SATO, 1997, p.81).

Anos mais tarde, em 1972, aconteceu um dos marcos desta temática, de 5 a 16 de junho daquele ano, iniciava a Conferência das Nações Unidas sobre o Meio Ambiente Humano, reunida em Estocolmo, Suécia, cuja finalidade foi estabelecer princípios para a melhoria do meio ambiente que até então tinha uma base enfraquecida naquele momento, dessa forma, definindo novos rumos para a Educação Ambiental e criando também o Programa das Nações Unidas para o Meio Ambiente ou PNUMA, sediado em Nairóbi (SILVA; CARNEIRO, 2017).

Já no ano de 1975, ocorreu o segundo evento relacionado ao meio ambiente, o Encontro Internacional de Educação Ambiental, o qual resultou na Carta de Belgrado: "nela 
foi definido que a Educação Ambiental deve ser multidisciplinar, continuada e integrada às diferenças regionais e voltada para os interesses nacionais" (TANNOUS; GARCIA, 2008 p.196).

Posteriormente, no ano de 1977, teve início a Conferência Intergovernamental sobre Educação Ambiental de Tbilisi, realizada na Geórgia. Essa conferência foi uma das mais marcantes relacionadas ao meio ambiente naquela época, tendo em vista que nela foram abordadas questões como os princípios, táticas e objetivos para a Educação Ambiental mundial, além de estimular a conscientização e compreensão dos problemas ambientais da atualidade, formando assim uma mudança de atitudes perante o meio (SILVA; CARNEIRO, 2017).

Adentrando na década de 1980, a Educação Ambiental contou com algumas mudanças, tendo em vista que naquele momento buscava-se maior disseminação referente à temática, sendo realizados diversos eventos para concretizar este objetivo, fazendo com que o tema ficasse mais popular entre a sociedade (SATO, 1997). Nesta mesma década, em 1987, aconteceu a Conferência de Moscou, em que se reuniram centenas de ambientalistas de vários países buscando compreender quais eram as dificuldades encontradas naquele momento referente ao meio ambiente, bem como promover a conscientização dos indivíduos e difundir os conceitos para a sociedade (TANNOUS; GARCIA, 2008).

No Brasil, ocorreu a Rio 92, sendo esta um marco na época, uma vez que - não diferente das demais - havia pressupostos semelhantes, ou seja, a preocupação com o meio ambiente. Assim, esta conferência resultou no Tratado de Educação Ambiental para Sociedades Sustentáveis e Responsabilidade Global, reconhecendo a Educação Ambiental como dinâmica, transformando o meio em que vivemos, afirmando que ela veio para criar nos indivíduos melhores condições de vida, por isso deve perpetuar-se por muitos anos (ZANARDI, 2010).

Logo, quando se fala da Educação Ambiental no território brasileiro, depara-se com inúmeros percalços vividos até a sua consolidação, assim ela foi formalmente reconhecida a partir da lei federal de $n^{\circ} 6.938$ sancionada em 31 de agosto de 1981, com a criação da Política Nacional do Meio Ambiente - PNMA (BRASIL, 1981).

\section{A importância da Educação Ambiental no ambiente escolar}

Hoje em dia, há leis que amparam a Educação Ambiental na Rede Escolar de Ensino, tal qual fora das escolas, por meio das quais diversos autores citam a importância da inclusão deste tema na realidade do aluno, pois assim que o meio social será transformado.

Contudo, percebe-se que este ensino tornou-se precário, já que acabou sendo distorcidas algumas práticas dos conceitos, fazendo com que este tema apareça somente nas aulas de Ciências uma vez no ano durante a Semana do Meio Ambiente, e depois sendo esquecida no decorrer do ano letivo (RAMOS, 1996).

Esse acaba sendo um dos grandes desafios dessa temática; no entanto, revisitando o trabalho de Lucatto e Talomani (2018), verificou-se que os autores relataram professores 
desenvolvendo a Educação Ambiental esporadicamente, uma maneira mais tradicional e de certa forma descontextualizada da realidade local, não havendo quaisquer articulações entre as disciplinas.

Observou-se que esse processo torna-se negativo para a aprendizagem dos alunos, uma vez que é importante o resgate constante do conteúdo, para que haja assimilação maior da temática, pois abordar essa temática pontualmente é recorrente nas salas de aulas, e por isso que trabalhar com os docentes é imprescindível a fim de sensibilizá-los para transformar as suas práticas (STEIN, 2011).

Assim, percebe-se o quanto é importante os princípios ambientais para mudar a qualidade de vida do planeta Terra. Deste modo, espera-se que a Educação Ambiental esteja no cotidiano da população, começando pelas escolas, ampliando o seu conhecimento, suas habilidades e motivações para adquirir valores e atitudes necessárias para lidar com questões e problemas ambientais, bem como encontrar soluções sustentáveis (DIAS, 2003).

De tal modo, é especificado pelo MEC (2007) que a Educação Ambiental deve estar inclusa em todas as modalidades de ensino, sendo uma parceria criada entre pais, alunos, a direção da escola e os professores, todos devem preservar e cuidar do meio em que vivem, no qual todos devem ter uma consciência crítica da realidade, e por ser um tema que agrega muito conhecimento às práticas sociais, geram o empenho nas demais pessoas.

Portanto, é extremamente importante que na Educação Ambiental informal crie-se na comunidade um pertencimento de cuidar de algo que faz parte de sua realidade, do seu dia a dia. Por conseguinte, quando os docentes abordarem questões ambientais, devem utilizar exemplos de suas localidades, exemplos regionais até chegar aos grandes acontecimentos mundiais. Desta forma, os alunos poderão compreender o que se passa em sua realidade, e transmitirão aos demais de sua família, para que tenham maiores aptidões em adotar esses princípios e levarem para suas futuras gerações. Por isso, há uma necessidade de existir uma parceria entre a comunidade e a escola, a fim de que cheguem a resultados eficazes. Logo, este é um trabalho coletivo, em que um leva a informação para o outro por meio de pequenos gestos, dia após dia, valorizando cada conquista.

Destarte, tanto nas escolas públicas quanto nas privadas de todo o país, é previsto por lei que a Educação Ambiental seja discutido no ambiente escolar. É necessário que os professores explorem os objetivos da Educação Ambiental e seus conceitos de maneira inovadora para mudar o comportamento e atitude daquele aluno; assim, espera-se que este aluno faça a diferença nas suas futuras ações do seu cotidiano e ao longo de sua vida. As instituições de ensino contam, desde o ano de 1965, com a implementação da lei $n^{\circ} 4.771$ de 15 setembro de 1965, da qual sobrevém ser obrigatório que o livro didático contenha informação referente ao meio ambiente, trazendo acontecimentos contemporâneos a fim de tornarem os alunos sujeitos críticos (RIBAS; LEMOS; ANASTÁCIO, 2016).

\section{Metodologia}

A presente pesquisa foi desenvolvida pela Universidade Estadual do Norte do Paraná 
(UENP), Campus de Cornélio Procópio, por meio do curso de Especialização em Geografia e Desenvolvimento Regional, em duas Escolas Municipais da cidade de São Sebastião da Amoreira-PR, município que conta com uma população estimada em 8.847 habitantes (IBGE, 2019).

Para o desenvolvimento da pesquisa, baseamo-nos em Godoy (1995) que segue o caráter de pesquisa qualitativa, para tanto, utilizamos um questionário como instrumento de coleta de dados. O uso de questionário foi de acordo com Gil (2002), que o define como uma "[...] técnica de investigação composta por um conjunto de questões que são submetidas a pessoas com o propósito de obter informações", havendo a necessidade de formular questões objetivas para obtenção de respostas precisas sem haver dúvidas, tanto em perguntas quanto nas respostas obtidas. O nosso público-alvo, foram professores os quais atuam no Ensino Fundamental I das duas escolas municipais, aos quais aplicamos os questionários.

Isto posto, parte da análise realizada nesta pesquisa foi uma revisão de literatura direcionada às Leis que regem a Educação Ambiental e seus desdobramentos, tais como Lei Federal $n^{\circ}$ 6.938, de 31 de agosto de 1981; Lei Federal $n^{\circ}$ 9.795, de 27 de abril de 1999, além dos principais autores que desenvolvem pesquisas nessa área.

Após o entendimento teórico, foi realizada uma visita nas escolas, com permissão da Direção, para expor os objetivos da pesquisa e quais intervenções seriam propostas para as instituições, além de compreender como a equipe pedagógica se posicionaria frente à temática.

Para coleta de dados com os docentes, o questionário diagnóstico foi aplicado individualmente aos diferentes professores das duas escolas, procurando entender como estes abordam a temática, tanto sobre a frequência em desenvolvê-la, quanto às dificuldades e se há um trabalho multidisciplinar do corpo docente daquela instituição. Neste sentido, seguindo os pressupostos de Severino (2013) para levantar informações escritas por parte dos sujeitos pesquisados, com vistas a conhecer a opinião daqueles sobre os assuntos em estudo.

A fim de preservar o nome das escolas, foi feita a codificação em que a primeira escola visitada recebeu a denominação de escola E1. A instituição é bem equipada, muito espaçosa, contém lixeiras para os alunos separarem seus resíduos, parque para as crianças brincarem e alguns murais didáticos. Durante a visita fomos recebidos pela equipe pedagógica.

A segunda escola, denominada escola E2, é uma instituição nova com cerca de 20 anos de atividade, no entanto conta com os mesmos aspectos da primeira instituição com parque bem estruturado para as crianças, contém diversas lixeiras seletivas, as paredes do ambiente são decoradas com diversos murais, tornando-se um espaço aconchegante. Nessa segunda instituição, quem nos recebeu de maneira muito atenciosa foi a diretora da escola.

Logo após as visitas, realizou-se a aplicação dos questionários para os professores. Esses apresentavam 10 questões, sendo apenas uma aberta: Como você define a Educação Ambiental? 
Já as demais questões foram fechadas para que os docentes assinalassem de acordo com seus conhecimentos, sendo elas: Idade? Sexo? Você se sente apto para falar sobre este tema com os alunos? São ofertadas oportunidades para aprimoramento dos professores para trabalhar a temática no ambiente escolar? Gostaria de participar de alguma capacitação para abordar a Educação Ambiental com os alunos? Qual dos instrumentos você gostaria de participar para se aperfeiçoar sobre o tema? Você consegue incluir a Educação Ambiental em todas as disciplinas? Com qual frequência é abordada a Educação Ambiental em sala de aula? Como você aborda a Educação Ambiental com os alunos? Lembrando que todas essas questões continham alternativas de múltipla escolha para indicação das respostas.

Ao todo foram 24 professores que participaram da pesquisa, 23 deles do sexo feminino e um do sexo masculino (professor de Educação Física identificado como P1 1 na pesquisa), sendo 12 de cada instituição, as idades dos docentes foram variadas desde 26 a 60 anos. Após a coleta de dados dos questionários respondidos, esses foram transcritos e os fragmentos textuais foram analisados segundo o referencial da Análise Textual Discursiva - ATD (MORAES, GALIAZZI, 2006); extraiu-se informações referentes ao uso da Educação Ambiental em sala de aula e em suas disciplinas.

Para melhor apresentação desta Análise Textual Discursiva das questões e das informações transcritas e discutidas, realizou-se a identificação e codificação dos professores em P1, P2, P3... P24, para distinguir as respostas dos professores que participaram da pesquisa e quanto às questões codificou-se em Q1, Q2, Q3... Q10, para indicar a questão de origem da resposta analisada.

Em seguida, apresentaram-se os assuntos analisados, contendo fragmentos textuais que consolidaram o resultado da maioria dos respondentes. Posteriormente, foi relatada uma possibilidade interpretativa dos dados categorizados.

\section{Resultados e discussões}

Os resultados demonstraram que as duas instituições possuem realidades similares, pois após os procedimentos de coleta de dados, por meio de questionários, tabulação e análise das questões mais pertinentes, foi possível entender o que se passa dentro do ambiente escolar do município estudado quanto à temática Educação Ambiental e suas relações com outras ciências.

Ao focar a análise na questão aberta "Como você define a Educação Ambiental?" observou-se que alguns docentes apresentam um conhecimento extremamente superficial referente a esta temática. Um exemplo é o fragmento textual "Natureza (elementos naturais)" de $\mathrm{P} 1, \mathrm{E} 1$. No entanto, há respostas mais próximas da compreensão científica "Como formação de indivíduos para proteger o meio ambiente para que as gerações futuras não "sofra" as consequências de ter um planeta poluído" (P19, E2), estas falas mostram desigualdade de conhecimento entre os professores que atuam nestas escolas, ao mesmo tempo que alguns possuem um preparo, já que a fala do segundo docente contempla o que a UNESCO (2005, p. 44) propõe em seus princípios informando que "Educação Ambiental é 
uma disciplina bem estabelecida que enfatiza a relação dos homens com o ambiente natural, as formas de conservá-lo, preservá-lo e de administrar seus recursos adequadamente".

$\mathrm{Na}$ Lei Nacional da Educação Ambiental, no Art. $1^{\circ}$ (BRASIL, 1999), esta posto que "entendem-se por Educação Ambiental os processos por meio dos quais o indivíduo e a coletividade constroem valores sociais, conhecimentos, habilidades, atitudes e competências voltadas para a conservação do meio ambiente, bem de uso comum do povo, essencial à sadia qualidade de vida e sua sustentabilidade".

Analisando o Quadro 1, pode-se confirmar esta variação de conhecimento entre os professores, mas também é evidente que metade deles possuem elementos suficientes que os habilitam para realizar intervenções sobre Educação Ambiental e ter uma boa atuação em sala de aula, principalmente, da E2 na qual foram classificados oito dos professores com "Noções próximas à compreensão científica atual", havendo a necessidade de um trabalho de formação continuada com os demais, essencialmente na E1, uma vez que oito dos participantes foram classificados na Unidade de Análise "Noções distantes da compreensão científica atual ou Desconhecimento", havendo a necessidade de construção de conhecimentos com esses profissionais, podendo oferecer aos seus alunos melhor formação também.

Gouvêa (2006) relata em seu trabalho que é necessária uma reflexão quanto à formação de professores na temática de Educação Ambiental. Ela debate que é preciso, constantemente, refletir sobre a construção de um saber ambiental pautado pelo compromisso social e humano necessário à formação dos professores e à superação da dispedagogia ambiental.

É muito evidente a indicação pelos participantes da necessidade de desenvolver a conscientização ambiental dos alunos, para assim caminhar rumo à proteção, conservação e preservação do meio. Reis, Semedo e Gomes (2012) relataram esse mesmo fato em sua pesquisa dizendo sobre:

as necessidades de se conscientizar e modificar a mentalidade de todos, já que a Educação Ambiental é um processo em permanente construção e tem como objetivo promover a renovação da autoimagem e da percepção do indivíduo perante o mundo e a coletividade, a fim de possibilitar não só a aquisição de novos conhecimentos, mas o despertar de valores e execução de novas atitudes em relação ao ambiente (REIS; SEMEDO; GOMES, 2012, p. 47).

Quadro 1 - Categoria "Conceito de Educação Ambiental"

\begin{tabular}{|c|l|}
\hline $\begin{array}{c}\text { Unidades de } \\
\text { Análise }\end{array}$ & $\begin{array}{l}\text { Descrição: esta categoria reúne fragmentos textuais } \\
\text { dos professores que evidenciaram conceitos sobre } \\
\text { Educação Ambiental. }\end{array}$ \\
\hline & $\begin{array}{l}\text { - Natureza (elementos naturais) (E1, P 01). } \\
\text { - Necessária urgente (E1, P 08). } \\
\text { - Muito importante (E2, P13). } \\
\text {-Conhecimento (E1, P12). }\end{array}$ \\
\hline
\end{tabular}




\begin{tabular}{|c|c|}
\hline $\begin{array}{l}\text { Noções distantes da } \\
\text { compreensão } \\
\text { científica atual ou } \\
\text { Desconhecimento. }\end{array}$ & $\begin{array}{l}\text { - Importante, deve ser aplicada sempre com os alunos } \\
\text { (E2, P14). } \\
\text { - Muito importante, mas é pouco discutida (E1, P11) } \\
\text { - Muito necessária aos alunos principalmente na } \\
\text { educação infantil (E2, P15). } \\
\text { - Muito importante para a sobrevivência dos seres (E1, P } \\
\text { 09). } \\
\text { - Dever de cada um (E1, P 06). } \\
\text { - Importante (E1, P 05). } \\
\text { - Não sei definir (E2, P22). } \\
\text { - Conscientização (E1, P 03). }\end{array}$ \\
\hline $\begin{array}{l}\text { Noções próximas à } \\
\text { compreensão } \\
\text { científica atual }\end{array}$ & $\begin{array}{l}\text { - Processo que deve estar no dia a dia dos alunos, para } \\
\text { que conscientizemos eles a cuidar de nosso ambiente } \\
\text { (E2, P23). } \\
\text { - Como formação de indivíduos para proteger o meio } \\
\text { ambiente para que as gerações futuras não sofram as } \\
\text { consequências de ter um planeta poluído (E2, P19). } \\
\text { - Um tema muito importante para ser trabalhado com os } \\
\text { alunos, porque quanto mais cedo aprendemos a cuidar } \\
\text { do meio ambiente melhor (E1, P 02). } \\
\text { - Muito Importante para mostrar aos alunos que } \\
\text { precisamos cuidar do nosso meio (E1, P 10). } \\
\text { - Uma forma de preservar o meio ambiente (E1, P 07). } \\
\text { - Conscientização das pessoas em relação à preservação } \\
\text { do meio ambiente e também o desenvolvimento } \\
\text { sustentável (E1, P 04). } \\
\text { - Práticas para preservar o meio ambiente (E2, P17). } \\
\text { - Área de ensino para conscientização dos problemas } \\
\text { ambientais (E2, P18). } \\
\text { - Tema importante porque conscientiza os alunos a } \\
\text { cuidar do meio ambiente (E2, P21). } \\
\text { - Conscientização que não pode destruir o meio } \\
\text { ambiente (E2, P20). } \\
\text { - Ensinamentos sobre cuidar e preservar o ambiente que } \\
\text { vivemos (E2, P16). } \\
\text { - É uma área de ensino voltada para a conscientização } \\
\text { sobre os problemas ambientais e como combatê-los (E2, } \\
\text { P24). }\end{array}$ \\
\hline
\end{tabular}

Fonte: o próprio autor

Este desconhecimento e falta de noção sobre o conceito de Educação Ambiental da El é evidenciado na questão seis, pois $75 \%$ relatam a necessidade em participar de alguma capacitação. Essa ideia é reforçada na questão sete, já que $75 \%$ dos participantes citam que precisam realizar aperfeiçoamento sobre o tema por meio de curso, bem como25\% por meio 
de palestras.

No trabalho desenvolvido por Martins e Schnetzler (2018) por meio de um grupo de pesquisa, ações de formação com professores da educação básica e professores universitários, ficou evidente que a socialização das experiências de ensino auxiliaram os participantes em modificações nas suas práticas docentes, que de início foram pontuais e compartimentalizadas; já no decorrer do trabalho, as práticas sofreram alterações com a inclusão de temáticas socioambientais trabalhadas de forma crítica, contextualizada, permanente, contínua e participativa.

Por conseguinte, é perceptível a necessidade de se repensar uma formação continuada para os docentes. De acordo com Nóvoa (1995), é nesse momento de formação que os docentes podem aprimorar suas práticas, buscando novas técnicas, e conhecimentos. Desta forma, serão nesses momentos que os professores transformarão suas ações em sala em aulas mais ricas e prazerosas.

Sendo assim, é importante lembrar que, para esse tema ser mais proveitoso na formação do aluno, "o professor deve partir da prática social e buscar alterar qualitativamente a prática de seus alunos, enquanto agentes de transformação social" (BRANCO, 2007, p. 10).

Nesse sentido, reforçamos que não se pode abordar a Educação Ambiental de forma isolada sem se preocupar em articulá-la com a realidade em que vivemos atualmente. Pois, a partir daí que os indivíduos perceberão a gravidade do problema; assim, no ambiente escolar deve-se realizar a articulação da Educação Ambiental com as demais disciplinas. No entanto, como pode ser analisado no Gráfico 1 a seguir, verifica-se que a temática não é abordada de maneira interdisciplinar, pois neste caso em específico alguns participantes usaram apenas as disciplinas de Ciências e Geografia na ação. Todavia, muitos autores acreditam que este processo deve ir além dessas duas disciplinas citadas, desenvolvendo no aluno uma compreensão crítica e reflexiva, criando atitudes positivas e conscientes em relação ao meio, gerando melhor qualidade de vida para todos (BRANCALIONE, 2016). 
Gráfico 1 - Porcentagem de respostas dos professores das escolas municipais em relação à pergunta "Você consegue incluir a Educação Ambiental em todas as disciplinas?"

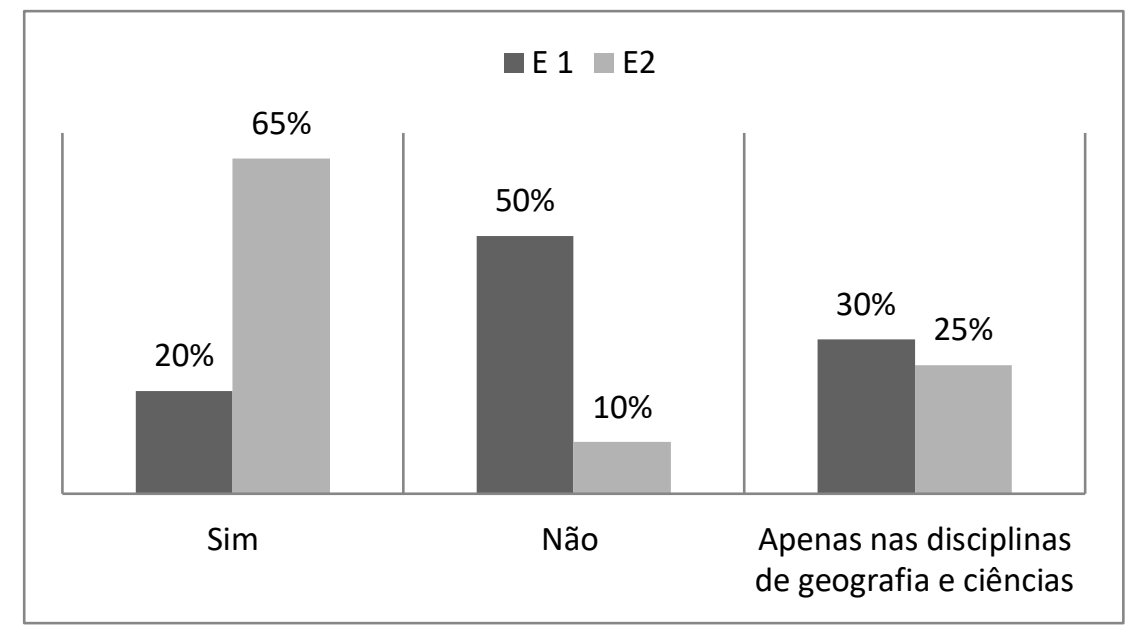

Fonte: o próprio autor

Nesse sentido, foi a partir da Conferência de Tbilisi (1977) que a Educação Ambiental passa a ser pensada de maneira interdisciplinar como mostra o fragmento dos autores Bernardes e Prieto (2010) que afirmam:

\begin{abstract}
a Educação Ambiental é o resultado de uma orientação e articulação de diversasdisciplinas e experiências educativas que facilitam a percepção integrada do meioambiente, tornando possível uma ação mais racional e capaz de responder àsnecessidades sociais(...) Para a realização de tais funções, a Educação Ambiental deveria suscita umavinculação mais estreita entre os processos educativos e a realidade, estruturandosuas atividades em torno dos problemas concretos que se impõem à comunidade;enfocar a análise de tais problemas, através de uma perspectiva interdisciplinar eglobalizadora, que permita uma compreensão adequada do problemas ambientais;(...).Recomendação n. ${ }^{\circ}$ 02Princípios básicosaplicar em enfoque interdisciplinar, aproveitando o conteúdo específico de cadadisciplina, de modo que se adquira uma perspectiva global e equilibrada (BERNARDES; PRIETO, p. 177).
\end{abstract}

Portanto, essa temática não deve ser levada ao aluno de maneira solta, e sim articulada entre as diferentes disciplinas. Contudo, percebe-se que isso está longe de acontecer no município de São Sebastião da Amoreira, uma vez que, além de estarem mais voltadas às disciplinas de Geografia e Ciências, não são abordadas constantemente, mas de forma pontual, como mostra o Gráfico 2. 
Gráfico 2 - Porcentagem de respostas dos professores das escolas municipais em relação à pergunta "Com qual frequência é abordada a Educação Ambiental em sala de aula?".

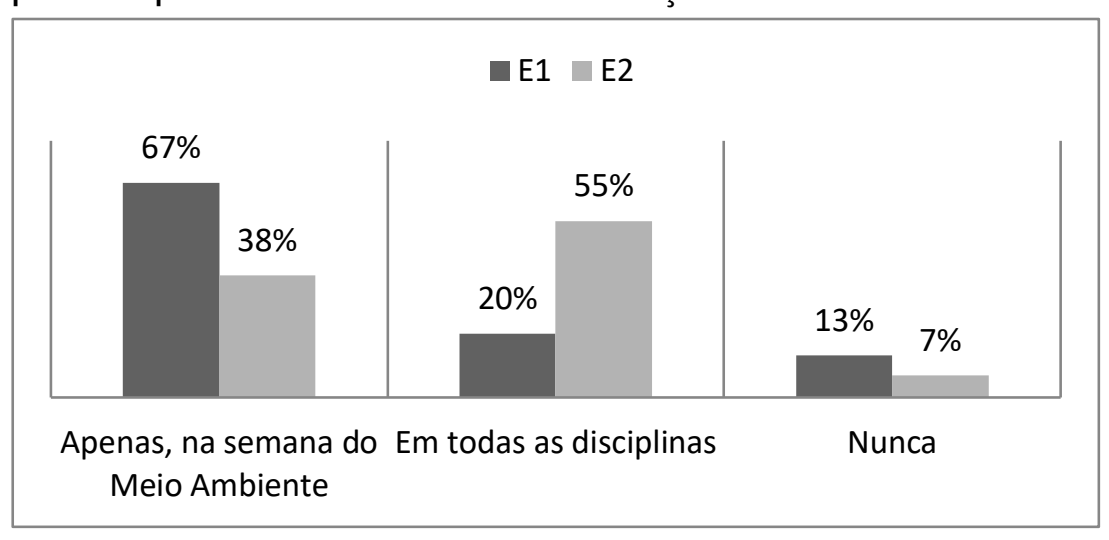

Fonte: o próprio autor

Relata-se, nesse estudo, que muitos professores ainda abordam a temática apenas em datas simbólicas, já que, em conversa com os docentes, esses afirmaram ter pouco tempo para tal abordagem, fazendo essa ser explanada de maneira esporádica ao longo do ano letivo sem o aprofundamento necessário. Além de que afirmaram outro motivo que faz com que ela seja discutida com menos frequência pelos docentes:a falta de material didático para a confecção de seus trabalhos manuais envolvendo essa temática. Como pode ser visto na fala da professora: "Na verdade, não temos incentivos para trazer esse assunto com os alunos em sala de aula, porque não recebemos capacitação adequada para fazer a discussão e quando queremos fazer um painel, ou outra atividade temos que colocar do nosso dinheiro que não é muito (risos)". Completando: "todo preparo que 'trago' é por causa de minhas buscas em sites da internet e não em capacitação ofertada pelo governo". (P1, Q4).

Essa busca do professor para melhor servir seu aluno está presente também nestas falas e isso só reforça o papel do professor em analisar permanentemente e repensar constantemente quanto às necessidades que formam a sociedade contemporânea e que o obriga a uma formação capaz de tornar o estudante independe para construir a sua vida laboral. Nossos mestres são parte da teia de produção destas concepções de ambiente; havendo, portanto, uma constante busca de conhecimentos por meio da formação continuada e desenvolvida de forma compartilhada, alicerçada nos conhecimentos prévios dos docentes, bem como nos aspectos essenciais que emergem em cada comunidade (DALFARRA, 2004).

Nesse sentido, essencialmente sobre a frequência da abordagem em sala de aula, Guimarães afirma que "a Educação Ambiental deve ser um processo contínuo e permanente, iniciando em nível pré-escolar e estendendo-se por todas as etapas da educação formal ou informal" (GUIMARÃES, 1995 apud MEDEIROS et al. 2011). Reforçando oque está relatado na Lei Nacional da Educação Ambiental (BRASIL, 1999) de que se deve trabalhar a Educação 
Ambiental tanto nas escolas como fora dela.

Já Medeiros et al. (2011, p. 02) relatam que a Educação Ambiental nas séries iniciais, as questões ambientais:

(...) estão cada vez mais presentes no cotidiano da sociedade, contudo, a Educação Ambiental é essencial em todos os níveis dos processos educativos e em especial nos anos iniciais da escolarização, já que é mais fácil conscientizar as crianças sobre as questões ambientais do que os adultos.

Seguindo com o raciocínio do mesmo autor, completa dizendo que,

finalmente, a Educação Ambiental nas séries iniciais do ensino fundamental ajuda a consciência de preservação e de cidadania. A criança aprende, desde cedo, que precisa cuidar, preservar, pois a vida do planeta depende de pequenas ações individuais que fazem a diferença ao serem somadas, as pequenas atitudes, que "vira uma bola de neve" e proporciona a transformação do meio em que mora. (MEDEIROS et al. 2011, p. 09).

Dessa maneira, buscou-se melhor entendimento observando outro ponto que é muito importante para esta pesquisa, compreender quais instrumentos metodológicos os professores utilizam com seus alunos para abordar essa temática. Houve evidências marcantes em que os professores não abordam os conteúdos e as realidades locais com frequência e, quando discutidos, acabam partindo de exemplos longe da realidade do aluno, esse aspecto acaba sendo negativo para o ensino-aprendizagem deles. Tendo em vista o que foi supracitado, quando se parte da realidade da criança, as chances de aprendizagem são muito significativas, como observa-se no Gráfico 3.

Kusset al. (2015) relatam em seu livro que a pesquisa está crescendo e deve ser a base para os professores que trabalham Educação Ambiental com seus alunos, debatem também que é importante o uso de metodologias de ensino para o desenvolvimento da Educação Ambiental nas escolas, pois assim tanto o ensino quanto a aprendizagem serão mais eficientes. 
Gráfico 3 - Porcentagem de respostas dos professores das escolas municipais em relação à pergunta "Como você aborda a Educação Ambiental com os alunos?"

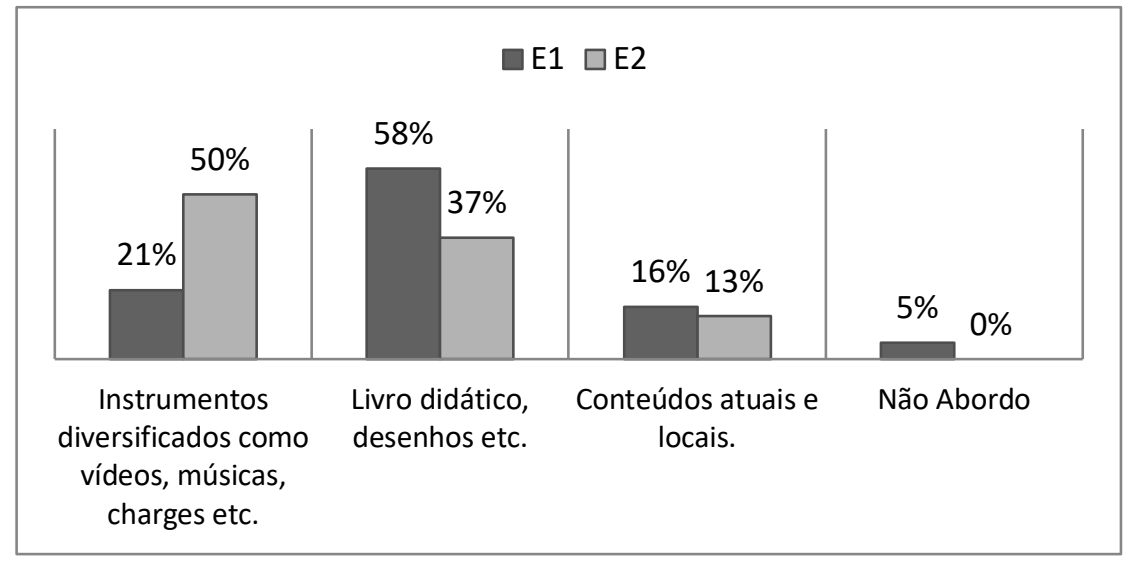

Fonte: o próprio autor

Por fim, é importante valorizar a experiência dos alunos, Dewey (1973, p. 17) afirma que "a experiência alarga, desse modo, os conhecimentos, enriquecem o nosso espírito e dá, dia a dia, significação mais profunda à vida". Concordando com o autor, Boud (apud Jarvis 2006) declara que a experiência é o resultado de um evento ou processo em que a pessoa sente, pensa, age e conclui no momento e imediatamente depois. Logo, é importante que o aluno veja que o assunto diz respeito ao local em que ele e a família vivem, reforçando as atividades de seu cotidiano, para que assim faça sentido e tenham condições de cuidar daquele local.

\section{Conclusão}

Retratar a temática ambiental contemporaneamente não é uma tarefa simples, ao contrário, é uma tarefa árdua que necessita do empenho de todos os envolvidos, e de ações contínuas para que gerem resultados significativos no meio em que vivemos, principalmente, na atualidade. Assim, espera-se que o ambiente escolar desempenhe uma função fundamental para trabalhar esse tema com os alunos, independente do nível escolar, no entanto, isso acaba ficando apenas no papel. Já que, na realidade, é um tanto quanto tumultuosa, pois alguns professores não enxergam esse tema com a seriedade que necessita.

Trabalhar a Educação Ambiental no contexto escolar tem sido um desafio em vários locais do meio social, tendo em vista inúmeros fatores apontados pelos diversos autores que estudam esse viés, diz respeito à fragilidade com que os docentes abordam essa temática em sala de aula. Na busca de respondermos o objetivo de compreender como os 
professores do Ensino Fundamental I abordam a Educação Ambiental com seus alunos, percebemos que os professores de nossa pesquisa trabalham essa temática somente em datas simbólicas ou de forma pontual, bem como se utilizam de exemplos distantes da realidade do aluno e ineficazes para mudar o comportamento do estudante e melhorar as condições em seu entorno.

$\mathrm{Na}$ abordagem da Educação Ambiental é importante conhecimento sobre conceito do que é Educação Ambiental e mesmo havendo uma variação deste conhecimento entre os professores da pesquisa, possuem elementos suficientes que os habilitam realizar intervenções sobre o tema e ter uma boa atuação em sala de aula.

Já em relação as suas práticas, percebemos que ainda há uma abordagem pontual e inconstante, havendo predominância destas ações voltadas às disciplinas de Geografia e Ciências.

Por isso, faz-se necessário que os docentes atualizem suas práticas e conhecimentos por meio da formação continuada, a fim de melhorar o processo de ensino no qual estão inseridos. Dessa forma, este trabalho nos fez compreender a dinâmica das escolas do município de São Sebastião da Amoreira, possibilitando elencar suas fragilidades na questão da Educação Ambiental.

\section{Referências}

BERNARDES, Maria Beatriz Junqueira; PRIETO, Élisson Cesar. Educação Ambiental: disciplina versus tema transversal. In:Revista Eletrônica do Mestrado em Educação Ambiental, Rio Grande, RS, v. 24, p.173-185, 2010. Disponível em: https://periodicos.furg.br/remea/article/view/3891/2321. Acesso em: 01 jun. 2019.

BRANCALIONE, Leandro. Educação Ambiental: refletindo sobre aspectos históricos, legais e sua importância no contexto social rei.In:Revista de Educação do IDEAU, Getúlio Vargas, RS, v. 11 , n. 23, p.01-13, 23 jun. 2016. Disponível em:

https://www.ideau.com.br/getulio/restrito/upload/revistasartigos/358_1.pdf. Acesso em: 27 jun. 2018.

BRANCO, Cristina. Formação continuada de professores: focalizando relação teórico-prática. Londrina: [s. n.], 2007. p. 01-24. Disponível em:

http://www.gestaoescolar.diaadia.pr.gov.br/arquivos/File/producoes_pde/artigo_cristina_branco.p df. Acesso em: 01 jun. 2019.

BRASIL. Lei $n^{\circ}$ 6.938, de 31 de agosto de 1981. Dispõe sobre a Política Nacional do Meio Ambiente, seus fins e mecanismos de formulação e aplicação, e dá outras providências. Brasília, DF: Diário Oficial da União, 198].

BRASIL. Lei $\mathbf{n}^{\circ}$ 9.795, de 27 de abril de 1999. Dispõe sobre a Educação Ambiental, institui a Política Nacional de Educação Ambiental e dá outras providências. Brasília, DF: Diário Oficial da União, 1999.

BRASIL. Ministério da Educação. Vamos cuidar do Brasil: conceitos e práticas em educação 
ambiental na escola. Brasília, DF: MEC, 2007. Disponível em:

http://portal.mec.gov.br/dmdocuments/publicacao3.pdf. Acesso em: 26 jun. 2018.

MEDEIROS, Monalisa Cristina Silva; RIBEIRO, Maria da Conceição Marcolino; FERREIRA, Catyelle Maria de Arruda. Meio ambiente e educação ambiental nas escolas públicas, 2020. Disponível em:

http://www.ambitojurídico.com.br/site/?n_link=revista_artigos_leitura\&artigo_id=10267\&revista_ caderno=5. Acesso em: 07 dez. 2020.

DAL-FARRA, Rossano André. Educação e representações: configurações em rede na mídia e no ambiente. Pro-Posições, Campinas, v. 15, n. 3, p. 165-172, 2004.

DEWEY, John. Vida e Educação. São Paulo: Melhoramentos, 1973.

DIAS, Genebaldo Freire. Educação ambiental: princípios e práticas. 8. ed. São Paulo: Gaia, 2003.

DIAS, Genebaldo Freire. Educação ambiental: princípios e práticas. 5. ed. São Paulo: Global, 1998.

GIL, Antônio Carlos. Como elaborar projetos de pesquisa. 4. ed. São Paulo: Atlas, 2002.

GODOY, Arilda Schmidt. Introdução à pesquisa qualitativa e suas possibilidades: uma revisão histórica dos principais autores e obras que refletem esta metodologia de pesquisa em Ciências Sociais. In: Revista de Administração de Empresas, São Paulo, v. 35, n. 2, p. 57-63, mar/abr. 1995. Disponível em: http://www.scielo.br/pdf/rae/v35n2/a08v35n2.pdf. Acesso em: 16 nov. 2019.

GOUVEA, Giana Raquel Rosa. Rumo da formação dos professores para a Educação Ambiental. Educar em Revista, Curitiba,UFPR, n.27, p.163-179, 2006.

HOGAN, Daniel Joseph Crescimento populacional e desenvolvimento sustentável. In: Lua Nova: Revista de Cultura e Política, São Paulo, n.31, 1993. Disponível em: https://doi.org/10.1590/S0102-64451993000300004. Acesso em: 17 nov. 2019.

IBGE. Instituto Brasileiro de Geografia e Estatística. Censo Demográfico. 2010. Disponível em: http://www.censo2010.ibge.gov.br/resultados_do_censo2010.php. Acesso em: 10 maio 2019. JARVIS, Peter. Towards a Comprehensive Theory of Human Learning: lifelong Learning and the learning society. New York: Routledge, 2006.

KUSS, Anelise Vicentini; CARLAN, Francele de Abreu; BEHLING, Greici Maia; GIL, Robledo Lima. Possibilidades metodológicas para a pesquisa em educação ambiental. Pelotas: Editora e Cópias Santa Cruz, 2015. 160 p. ISBN: 978-85-61629-75-5.

KRÜGER, Eduardo Leite. Uma abordagem sistêmica da atual crise ambiental. Desenvolvimento e Meio Ambiente, Curitiba, UFPR, n. 4, p. 37-43, jul/dez 2001.

LUCATTO, Luiz Gustavo; TALAMONI, Jandira Liria Biscalquini. A construção coletiva interdisciplinar em educação ambiental no ensino médio: a microbacia hidrográfica do Ribeirão dos Peixes como tema gerador. Ciências \& Educação, Bauru, SP, v.13, n.3, p.389-398, 2007.

MARTINS, José Pedro de Azevedo; SCHNETZLER, Roseli Pacheco. Formação de professores em educação ambiental crítica centrada na investigação-ação e na parceria colaborativa. In:Ciência \& Educação, Bauru, SP, v. 24, n. 3, p. 581-598, 2018.

MEDEIROS, Aurélia Barbosa de;MENDONÇA, Maria José da Silva Lemes; SOUSA, Gláucia Lourenço de; 
OLIVEIRA, Itamar Pereira de.. A Importância da educação ambiental na escola nas séries iniciais. Revista Faculdade Montes Belos, Montes Belos, GO, v. 4, n. 1, p.01-17, set. 2011. Disponível em: http:/ / www.terrabrasilis.org.br/ecotecadigital/pdf/a-importancia-da-educacao-ambiental-naescola-nas-series-iniciais.pdf. Acesso em: 01 jun. 2019.

MORAES, Roque; GALIAZZI, Maria do Carmo. Análise textual discursiva: processo reconstrutivo de múltiplas faces. In: Ciência \& Educação, Bauru, SP, v. 12, n. 1, p. 117-128, 2006. Disponível em: http://www2.fc.unesp.br/cienciaeeducacao/include/getdoc.php?id=801 \&article =154\&mode=pdf. Acesso em: 5 março. 2020.

PELICIONI, Maria Cecília Focesi. Educação Ambiental, Qualidade de Vida e Sustentabilidade.

Educação ambiental, Qualidade de Vida e Sustentabilidade: Saúde e Sociedade, São Paulo, p.19-31, 1998. Disponível em: http://www.scielo.br/pdf/sausoc/v7n2/03. Acesso em: 27 jun. 2018.

RAMOS, Elisabeth Christmann. Educação Ambiental: evolução histórica, implicações teóricas e sociais: uma avaliação crítica. 1996. 147 f. Dissertação (Mestrado em Educação na área de Concentração de Educação e Trabalho) - Universidade Federal do Paraná, Curitiba, 1996. Disponível em: https://acervodigital.ufpr.br/bitstream/handle/1884/29517/DELISABETH

CHRISTMANNRAMOS.pdf? sequence $=1$. Acesso em: 26 jun. 2018.

REIS, Luiz Carlos Lima; SEMÊDO, Luzia Teixeira de Azevedo Soares; GOMES, Rosana Canuto. Conscientização Ambiental: da Educação Formal a Não Formal. Revista Fluminense de Extensão Universitária, Vassouras, v. 2, n. 1, p. 47-60, jan./jun., 2012.

RIBAS, Luiz César; LEMOS, Stella Vanucci; ANASTÁCIO, Loreanna Bertolucci de Araújo. Bases para políticas de educação ambiental no Brasil: perspectiva histórico-cronológica. Pedagog. Foco, Iturama, MG, v. 11, n. 5, p.120-135, 2016. Disponível em: revista.facfama.edu.br/index.php/PedF/article/download/174/168. Acesso em: 27 jun. 2018.

SATO, Michele. Educação para o ambiente amazônico. 1997. 246 f. Tese (Doutorado em Ecologia e Recursos Naturais, Ciências Biológicas) - Universidade Federal de São Carlos, São Carlos, 1997. Disponível em: http://www.lapa.ufscar.br/pdf/tese_doutorado_michele_sato.pdf. Acesso em: 28 jun. 2018.

SEVERINO, Antônio Joaquim. Metodologia do trabalho científico. 23. ed. rev. e atual. São Paulo: Cortez, 2007

SILVA, Carlos Kleber F. da; CARNEIRO, Conceição. Um breve histórico da Educação Ambiental e sua importância na escola. In: Congresso Nacional De Educação, (4), 2017, João Pessoa, Paraíba.

Anais[...]. v. 5, p. 01-11. Disponível em:

https://editorarealize.com.br/revistas/conedu/trabalhos/TRABALHO_EV073_MD1_SA14_ID9579_12 102017144004.pdf. Acesso em: 04 jul. 2018.

STEIN, Dionisia dos Santos. Ações Educativas Ambientais no Cotidiano de Uma Escola Municipal de Santa Maria - RS. 2011.45 f. Monografia (Especialização em Educação Ambiental) - Universidade Federal de Santa Maria, Santa Maria, 2011. Disponível em:

https://repositorio.ufsm.br/bitstream/handle/1/288/Stein_Dionisia_dos_Santos.pdf?sequence=1 \&i sAllowed=y. Acesso em: 06 dez. 2020.

TANNOUS, Simone; GARCIA, Anice. Histórico e evolução da Educação Ambiental através dos 
tratados internacionais sobre o meio ambiente. Nucleus, [S.I.],Fundação Educacional de Ituverava, v. 5, n. 2, p.183-195, 30 nov. 2008. Disponível em: http://dx.doi.org/10.3738/1982.2278.131. Acesso em: 04 jul. 2018.

UNESCO. Década da Educação das Nações Unidas para um Desenvolvimento Sustentável, 20052014: documento final do esquema internacional de implementação, Brasília, DF, Brasil, 2005. 120 p.

ZANARDI, Belisa Neves. Concepções de Educação Ambiental de graduandas em Pedagogia. 2010. 127 f. Trabalho de Conclusão de Curso (Graduação em Ciências Biológicas) - Faculdade Presbiteriana Mackenzie, São Paulo, 2010. Cap. 1. Disponível em: http:/ / www.mackenzie.br/fileadmin/Graduacao/CCBS/Cursos/Ciencias_Biologicas/10_2012/Bibliot eca_TCC_Lic/2010/10_2010/BELISA.pdf. Acesso em: 23 jun. 2018.

\section{Suellen Jane Correia}

Mestranda do Programa de Pós-Graduação em Geografia da Universidade Estadual de Londrina (UEL, 2019-2020), graduada em Geografia pela Universidade Estadual do Norte do Paraná (UENP 2016), especialista em Educação Especial Inclusiva; Geografia e História; Geografia e Desenvolvimento Regional. Atualmente é bolsista CAPES e integrante do Grupo de estudos em ensino de geografia e educação ambiental - GEENGEA. E-mail: suellen_correial1@hotmail.com. ORCID: http://orcid.org/0000-0001-8039-3307.

\section{Rodrigo de Souza Poletto}

Biólogo com Doutorado em Ciências Biológicas. Professor do Programa de Pós-Graduação em Ensino (PPGEN) na Universidade Estadual do Norte do Paraná (UENP). Participantes do Grupo de Pesquisa em Ensino e Formação de Profissional - GPEFOP. E-mail: rodrigopoletto@uenp.edu.br. ORCID: http://orcid.org/0000-0002-7034-7865. 